\section{(1) \\ CrossMark}

\title{
Indoor mould exposure, asthma and rhinitis: findings from systematic reviews and recent longitudinal studies
}

\author{
Denis Caillaud ${ }^{1}$, Benedicte Leynaert ${ }^{2,3}$, Marion Keirsbulck ${ }^{4}$ and \\ Rachel Nadif $\mathbb{1}^{5,6}$ on behalf of the mould ANSES working group ${ }^{7}$
}

\begin{abstract}
Affiliations: ${ }^{1}$ Pulmonary and Allergology Dept, CHU Clermont-Ferrand, Clermont Auvergne University, Clermont-Ferrand, France. ${ }^{2}$ INSERM, UMR1152, Pathophysiology and Epidemiology of Respiratory Diseases. Epidemiology, Paris, France. ${ }^{3}$ Univ Paris Diderot Paris 7, UMR 1152, Paris, France. ${ }^{4}$ ANSES (French Agency for Food, Environmental and Occupational Health and Safety), Maisons-Alfort, France. ${ }^{5}$ INSERM, U1168, VIMA: Ageing and Chronic Diseases, Epidemiological and Public Health Approaches, Villejuif, France. 'Univ Versailles St-Quentin-en-Yvelines, UMR-S 1168, Montigny le Bretonneux, France. ${ }^{7} \mathrm{~A}$ full list of the ANSES working group can be found in the Acknowledgements.
\end{abstract}

Correspondence: Denis Caillaud, Pulmonary Dept, G. Montpied Hospital, 58 Montalembert Street, 63003 Clermont-Ferrand Cedex, France. E-mail: dcaillauddachu-clermontferrand.fr

@ERSpublications

Evidence that indoor mould at home increases asthma in children is accumulating but is still insufficient in adults http://ow.ly/nEnt30j7lco

Cite this article as: Caillaud D, Leynaert B, Keirsbulck M, et al. Indoor mould exposure, asthma and rhinitis: findings from systematic reviews and recent longitudinal studies. Eur Respir Rev 2018; 27: 170137 [https://doi.org/10.1183/16000617.0137-2017].

ABSTRACT Starting from the Institute of Medicine (IOM) and World Health Organization (WHO) reports, this review provides an overview of the literature published from 2006 to 2017 on the associations between indoor mould exposure and asthma and rhinitis separately in children and adults with a focus on longitudinal epidemiological studies.

A systematic search of peer-reviewed literature was performed, including systematic reviews and metaanalyses, longitudinal, incident case-control and panel studies. 61 publications were identified reporting visible mould or mould odour or quantitative assessment of culturable fungi or mould species.

In children, visible mould and mould odour were associated with the development and exacerbations of asthma, providing sufficient evidence of a causal relationship. Results from population-based studies in adults were too few and divergent to conclude at more than a limited level of evidence. Exposure to mould in a work building was associated with the incidence and exacerbations of occupational asthma, and we concluded at a sufficient evidence for an association. Systematic reviews, meta-analyses and longitudinal studies on the relationships between mould exposure and allergic rhinitis provide sufficient evidence of an association.

This review extended the conclusions of the IOM and WHO reports, and highlighted the need for further longitudinal studies on asthma in adults, and on rhinitis.

\section{Introduction}

Providing good air quality is a measure with the potential to improve lung and general health [1]. Among preventable risk factors, there is a growing interest in the effect of exposure to dampness and visible mould at home. A recent review estimated the cost to society, corresponding to total economic burden of disease

This article has supplementary material available from err.ersjournals.com

Received: Dec 192017 | Accepted after revision: March 152018

Provenance: Submitted article, peer reviewed.

Copyright CERS 2018. ERR articles are open access and distributed under the terms of the Creative Commons Attribution Non-Commercial Licence 4.0. 
with cost of illness, and willingness to pay attributable to dampness and mould in the USA to be USD 15.1 (9.4-20.6) billion for asthma morbidity, and USD 3.7 (2.3-4.7) billion for allergic rhinitis [2].

In 2004, the Damp Indoor Spaces and Health Committee of the Institute of Medicine (IOM) reviewed and summarised the scientific evidences for relationships between indoor air exposure and the development and exacerbations of asthma [3]. It concluded that there was sufficient evidence of an association between damp indoor exposure and certain respiratory health outcomes, but insufficient evidence to determine whether an association exists between the presence of mould and asthma development. In 2009, the World Health Organization (WHO) [4] considered that the level of evidence was sufficient in favour of causality for asthma development and almost sufficient for asthma exacerbation without distinction between children and adults.

In the past decade, several meta-analyses and specific reviews have investigated the associations between indoor exposure to mould and respiratory health. These reviews, and more particularly the meta-analyses have provided useful estimates for the increased risk of asthma or rhinitis associated with exposure to mould. New data available in these reviews led to the conclusion that there was sufficient evidence of an association between qualitative mould exposure in indoor environments and asthma development, especially in children, but the authors emphasised the need for further work [5-10]. Indeed, results from cross-sectional and longitudinal studies were often pooled in these reviews, and thus if an association was observed the temporal sequence could not be ascertained. Furthermore, the analyses used a rather broad definition of exposure: the association was related to mould exposure or to dampness [4]. Finally, studies in adults were not included or were grouped together with studies in children, despite the possible difference in the risk factors of adult-onset and childhood-onset asthma.

The aim of the present review was to provide an overview of papers published from 2006 to 2017 on the effect of indoor mould exposure on asthma and rhinitis specifically. Studies reporting only on the health effect of dampness, with no specific focus on mould exposure, were not included in our review. The review focused on longitudinal studies, with a separation of findings from qualitative and quantitative studies, and from studies in children and adults. The search covered any indoor environment, including the workplace.

\section{Methods}

This review is one of the deliverables of a working group of 13 experts commissioned by the French Agency for Food, Environmental and Occupational Health and Safety (ANSES) to give an expertise on the exposure to mould in indoor environment (see detailed information in the online supplementary material). A full report was published in French in August 2016 [11] and a short version of the ANSES opinion is available in English [12].

Taking as a starting point the last report of the French Higher Council for Public Health [13] published in 2006, and the WHO report covering publications up to 2007, a systematic review of publications on the health effect of indoor mould exposure from January 2006 to November 2017 was conducted. The literature search used computerised bibliographic databases (PubMed and Scopus). The analysis of literature was performed in four steps according to the four-phase flow diagram of the PRISMA (Preferred Reporting Items for Systematic Reviews and Meta-Analyses) statement: identification, screening, eligibility and inclusion as illustrated in figure E1. We chose "mold" and "fungi" as keywords not including microbial, moisture or bio-contaminant. For Pubmed, the search was also based on nine MESH terms: "fungi/adverse effects", "fungi/epidemiology", "fungi/growth and development", "fungi/immunology", "fungi/physiopathology", "fungi/toxicity", "fungi/pathology", "occupational health/epidemiology" and "occupational health/toxicity". For Scopus, the search was based on three groups of free terms: 1) health",

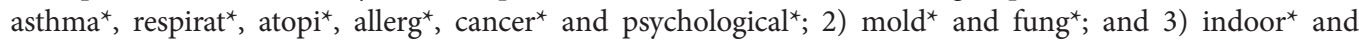
expos* ${ }^{\star}$. We identified 4967 records after excluding duplicates.

After screening, 518 records were selected as follows. 1) We selected epidemiological studies investigating home, office, school and hospital as indoor environments; 2) we selected "mould exposure" as qualitative data: visible dampness if combined with mould exposure, mould exposure or mould odour, or quantitative mould species: specific or total culturable fungi, mould components such as extracellular polysaccharides, ergosterol, glucans and molecular tools (quantitative (q)PCR); and 3) we selected the following respiratory health outcomes showing the most comprehensive effect: respiratory symptoms, wheeze, asthma symptoms, exacerbations and development of asthma and allergic and nonallergic rhinitis, not including specific search terms for biomarkers of respiratory health.

We further included only records on symptoms due to mould exposure by inhalation leading to 485 eligible full-text articles.

Final inclusion criteria were longitudinal studies, incident case-control studies, panel studies, systematic reviews and meta-analyses leading to the review of 61 papers. 
The working group classified strength of evidence using the same categories as those found in the IOM and WHO reviews. In addition to the studies included in the present review, animal data and toxicological data dealing mainly with potential mechanisms behind the observed health effect were considered in interpreting the evidence of health effect due to mould exposure. A set of criteria was used for the assessment of evidence based on HiLL's [14] criteria: strength of association, biological gradient, consistency of association, biological plausibility and coherence and temporally correct association $[3,4]$. New findings extended the conclusions of the IOM and WHO reports and are summarised in table E3.

\section{Results}

The literature search identified 4967 publications, of which 61 reported relevant exposures and health outcomes in suitable study populations (figure E1). Seven meta-analyses and four systematic reviews were identified [5-10, 15-19]. While in 2007, FISK et al. [15] concluded that there was insufficient evidence of an association between mould and asthma development and sufficient evidence for asthma exacerbations in sensitised asthmatic subjects, subsequent reviews progressively identified new outcomes or specific exposure that led to the conclusion that there was sufficient evidence. Figure 1 shows the odds ratios (ORs) for the association between mould exposures and asthma development derived from the meta-analyses, with the number of studies selected. The strength of evidence for exacerbations of asthma was stronger for associations between indoor dampness and mould with suggestive evidence of causality in children and sufficient evidence in adults $[6,16]$. Regarding quantitative exposure, there was limited evidence of an association for culturable fungi $[6,16]$. In a meta-analysis, SHARPE et al. [17] found that Aspergillus, Penicillium, Alternaria and Cladosporium species were present at higher concentrations in homes of patients with asthma symptoms (adjusted (a)OR 1.36, 95\% CI 1.02-1.82; I ${ }^{2}=61 \%$ ), but concluded that more work was needed on the role of fungal diversity.

Most recent reviews emphasise the need for further work. VeSPER and Wymer [18] reported the results of six epidemiological studies from United States that used the Environmental Relative Mould Index (ERMI), constructed from dust sample qPCR analysis of 36 indicator moulds [19] and studied its association with asthma: the authors concluded that the ERMI studies do not prove that there is a causal relationship between mould exposure and the development or exacerbation of asthma. Lastly, by focusing on tropical countries, PeI ZAM et al. [20] underlined that several studies dealing with children's respiratory health were undertaken in China, but were limited in Malaysia and Singapore. This last review indicated that

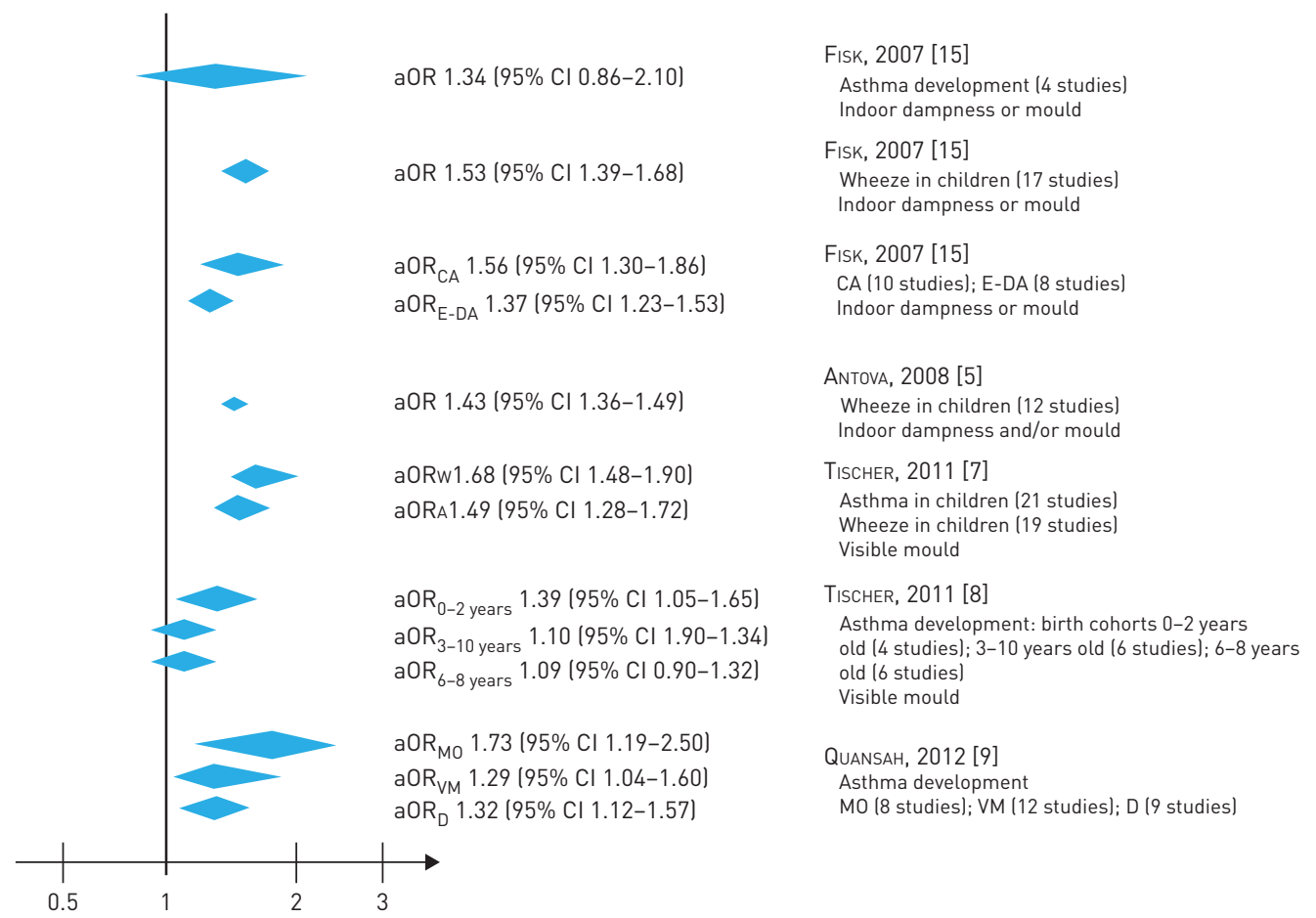

FIGURE 1 Adjusted odds ratios (aOR) and $95 \%$ confidence intervals for asthma development and wheeze from the meta-analyses. CA: current asthma; E-DA: ever-diagnosed asthma; W: wheeze; A: asthma; MO: mould odour; VM: visible mould; D: dampness. 
TABLE 1 Exposure to moulds using qualitative metrics and asthma occurrence in children (longitudinal studies)

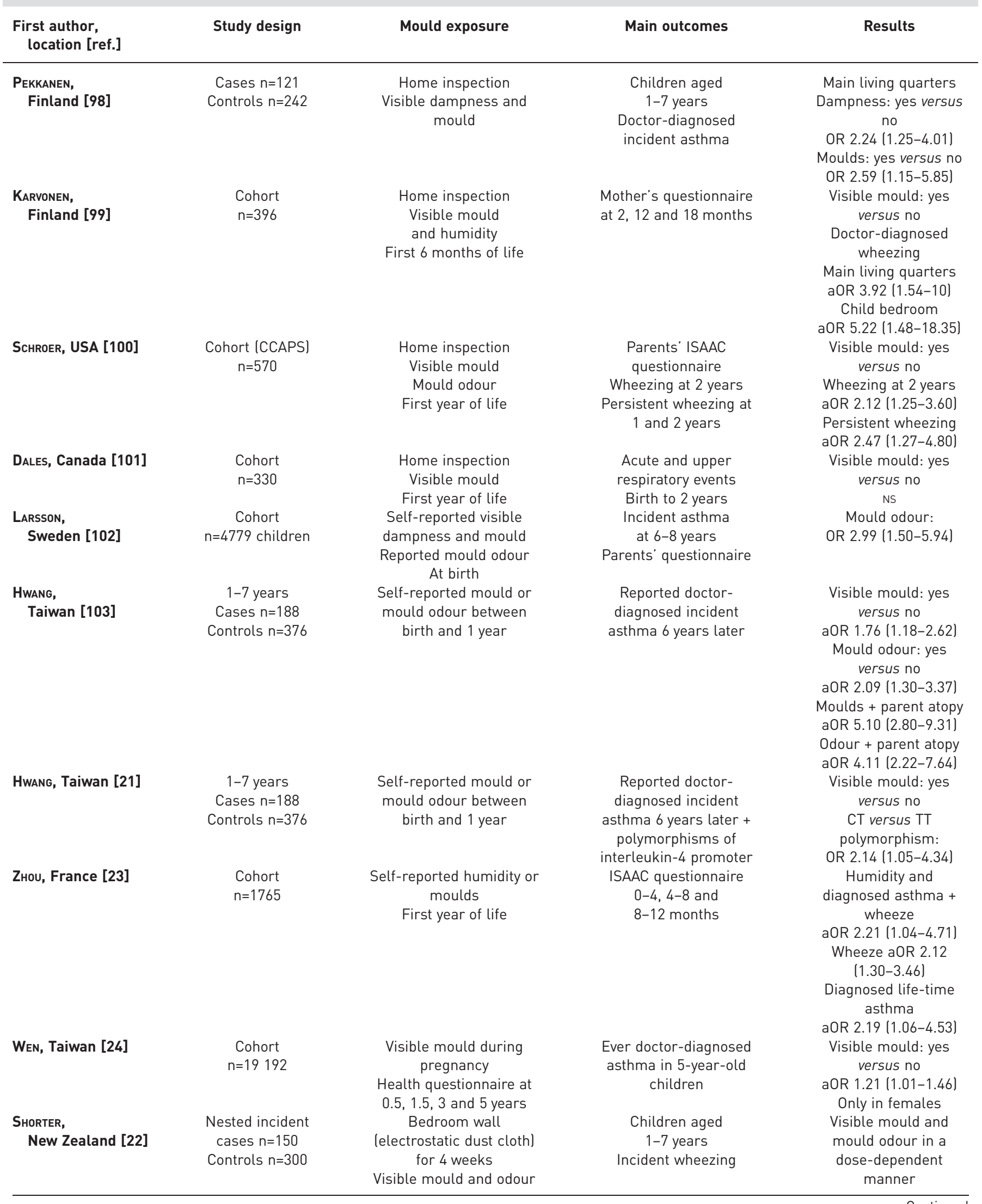


TABLE 1 Continued

\begin{tabular}{|c|c|c|c|c|}
\hline $\begin{array}{l}\text { First author, } \\
\text { location [ref.] }\end{array}$ & Study design & Mould exposure & Main outcomes & Results \\
\hline $\begin{array}{l}\text { KaRvonen, Finland } \\
\text { [25] }\end{array}$ & $\begin{array}{l}\text { Cohort } \\
n=398\end{array}$ & $\begin{array}{c}\text { Home inspection } \\
\text { Visible mould and } \\
\text { humidity } \\
\text { First } 6 \text { months of life }\end{array}$ & $\begin{array}{c}\text { Ever } \\
\text { physician-diagnosed } \\
\text { asthma } \\
\leqslant 6 \text { years }\end{array}$ & $\begin{array}{c}\text { Visible mould: yes } \\
\text { versus no } \\
\text { Living room } \\
\text { aOR } 7.51 \text { (1.49-37.83) } \\
\text { Child's bedroom } \\
\text { aOR } 4.82 \text { (1.29-18.02) } \\
\text { Allergic asthma } \\
\text { aOR 9.08 (1.95-42.23) }\end{array}$ \\
\hline $\begin{array}{l}\text { THACHER, } \\
\text { Sweden [26] }\end{array}$ & $\begin{array}{c}\text { BAMSE cohort } \\
\quad n=3798\end{array}$ & $\begin{array}{l}\text { Any self-reported mould } \\
\text { or dampness indicator } \\
\text { (dampness damage, } \\
\text { visible mould or mould } \\
\text { odour) in infancy } \\
\text { ( } 2 \text { months) }\end{array}$ & Asthma $\leqslant 16$ years & $\begin{array}{c}\text { Any indicator } \\
\text { Asthma } \\
\text { OR } 1.31 \text { (1.08-1.59) } \\
\text { Nonallergic asthma } \\
\text { aOR } 1.80 \text { (1.27-2.55) }\end{array}$ \\
\hline
\end{tabular}

aOR: adjusted odds ratio; CCAPS: Cincinnati Childhood Allergy and Air Pollution Study; ISAAC: International Study of Asthma and Allergies in Childhood; NS: nonsignificant; BAMSE: Barn/Child Allergy Milieu Stockholm Epidemiology.

dampness and mould in buildings were associated with various respiratory symptoms as well as onset of asthma, strongly suggesting moulds as the causal agents.

\section{Exposure to moulds using qualitative metrics and asthma occurrence in children llongitudinal studies)}

The publications selected addressed the relationship between dampness, visible mould, mould odour and respiratory health. They include two types of studies: birth cohort studies in children with several years of follow-up and studies involving incident asthma [4] (table 1).

We found six newly published studies not referenced in the previous reviews. In the first, incident asthma in older children was associated with reported visible mould and mould odour. This relationship was stronger in children carrying the CT genotype of the interleukin-4 promoter than in those carrying the TT genotype [21]. In the second study, observations of visible mould in New Zealand were strongly associated with new-onset wheezing, in children aged 1-7 years [22]. In the third, parent-reported dampness or moulds were associated with various asthma phenotypes, especially wheeze at 12 months [23]. In the fourth study [24], performed in 19192 mother-child pairs representative of the population of Taiwan, exposure to visible mould on the walls during pregnancy was independently associated with an increased risk of asthma diagnosed at the age of 5 years in females. In the fifth study, performed in Finland, exposures at an early age to moisture damage and mould in the child's main living room were associated with physician-diagnosed ever-asthma during the first 6 years [25]. In the last study, any self-reported mould or dampness indicator in infancy (2 months) was associated with asthma up to 7 years of age [26].

These studies confirm the review performed by QUANSAH et al. [9], whose findings showed the causal relationship between fungi, mainly in living rooms, and the occurrence of respiratory symptoms, especially asthma. The relationship was progressively stronger with visible mould and mould odour and more marked in children one of whose parents was atopic.

\section{Exposure to moulds using quantitative measured mould species or components and asthma occurrence in children (longitudinal studies)}

Analysis of epidemiological data shows that a large variety of methods were used for assessing mould exposure and indicators: mould components from indoor air or settled dust such as $(1,3)-\beta$-D-glucans, extracellular polysaccharides and ergosterol, as previously reported in reviews and meta-analyses. The most recent publications studied the relationship between fungal exposures measured by culture-based methods and molecular techniques and asthma occurrence in children (table E1).

Two fungal culture studies using data from the Boston birth cohort showed that wheezing at 1 year of age was associated with Alternaria and Cladosporium in dust [27] and asthma at the age of 13 years with airborne Alternaria [28]. The study by Rosenbaum et al. [29] indicated that Penicillium measured in the air 
at 3 months was associated with wheezing at 1 year. In contrast, the Boston birth cohort identified a protective effect of yeasts measured in bedroom dust samples taken at the age of 3 months on wheezing at 1 year, and on the development of asthma at 13 years.

In studies using molecular techniques, the risk of asthma was associated with a high ERMI score [19]. In a small case-control study, low fungal diversity was associated with increased risk of asthma development at the age of 7 years, but no significant associations were found with fungal levels [30]. In the LISA German birth cohort [31], exposure to higher fungal diversity in the living room in infancy, assessed using terminal restriction fragment length polymorphism, was associated with reduced risk of developing sensitisation at 6 years and ever-wheezing until the age of 10 years. However, these associations were no more significant in the longitudinal analyses considering the impact of several follow-ups and their correlation with each other. In a case-control incident asthma study performed in 1-7-year-old children in New Zealand, measurements of qPCR microbial levels in the bedroom children using electrostatic dust cloths were not associated with new-onset wheezing, in contrast to observations of visible mould [22].

In conclusion, given the small number of longitudinal studies, and their conflicting and inconclusive results, there is currently insufficient evidence to determine whether an association exists between quantitatively measured mould species or components and the occurrence of asthma.

Exposure to moulds and exacerbations of asthma in children (panel studies)

We found nine studies (table 2), six being already referenced in the recent reviews by KANCHONGKITTIPHON et al. [16], Sharpe et al. [17], Vesper and Wymer [18], and Pei Zam et al. [20]. Five out of the six panel studies investigated the evolution of asthma symptoms or changes in peak expiratory flow in asthmatic children exposed to mould for periods ranging from 2 weeks to 3 years. In these studies, an association, albeit modest, was consistently found between mould exposure in asthmatic children, in particular exposure to Penicillium, and an increased variability in peak expiratory flow rate, a higher asthma severity score, or an increase in the number of days with symptoms or in the unplanned hospital visits. Interestingly, in unadjusted analyses in children of unspecified atopic status, Wu et al. [32] found that high levels of total culturable fungi in dust were associated with an increased number of urgent care visits only in those with genetic polymorphisms that caused reduced enzymatic breakdown of chitin, an important fungal protein. This study provides biological plausibility for nonallergic mechanisms for exacerbation of asthma in relation to fungal exposures. Overall, these results, from studies performed in children with variable level of severity at baseline, show an increase in asthma activity associated with mould exposure, irrespective of the children's allergic sensitisation to moulds.

Although of small sample size, the first recent study showed an association between indoor Cladosporium levels in the child's bedroom and readmissions for asthma [33]. The second one showed that high fungal concentrations in the main living area in which the child spent the most time was associated with asthma severity [34]. After stratification according to atopy, the same association was found significant in nonatopic children. Interestingly, compared to mild asthma, the fungal communities in house dust from atopic children with severe asthma had low compositional variation, whereas no differences were found between homes of nonatopic children with severe compared to mild asthma. Lastly, among 419 children from 25 schools in three European countries, CASAS et al. [35] found that children with respiratory conditions report fewer symptoms and/or less severe respiratory symptoms during weekends and summer holidays compared with school days, the association being clearer among those attending schools with moisture damage problems.

In summary, all these studies provide strong evidence for associations between indoor mould exposure and exacerbation of asthma in children, with arguments for causality.

\section{Exposure to moulds using qualitative metrics and asthma in adults (longitudinal studies)}

To date, few longitudinal studies have investigated the relationships between mould exposure and respiratory health in adults. These studies were either not included in previous reviews or their findings were grouped together with those in children despite the fact that asthma development in adults may result from different risk factors than in children (table E2).

We only identified four longitudinal studies published after 2006. Owing to the scarcity of studies in adults, we decided to include one report that collected data on mould exposure, although only home dampness was included in the longitudinal analyses. Two studies were performed in northern Europe, and two studies were carried out as part of the European Community Respiratory Health Survey (ECRHS).

In a population-based incident case-control study in Finland, JAAKKOLA et al. [36] investigated the independent and joint effects of indoor exposure to mould and interior surface material and incident asthma. No independent association was observed for exposure to mould at home or at work. However, 
TABLE 2 Exposure to moulds and exacerbation of asthma in children (panel studies)

$\begin{aligned} & \text { First author, } \\ & \text { location }\end{aligned}$
[ref.]

\begin{tabular}{|c|c|}
\hline $\begin{array}{l}\text { HaGmolen OF TEN } \\
\text { HaVE, } \\
\text { the Netherlands } \\
\text { [104] }\end{array}$ & $\begin{array}{c}526 \text { children with } \\
\text { asthma (mean age } \\
11 \text { years) } \\
\text { Follow-up: } 2 \text { weeks } \\
\text { (2 visits) }\end{array}$ \\
\hline INAL, Turkey [105] & $\begin{array}{l}19 \text { children with } \\
\text { asthma or rhinitis, } \\
\text { and monosensitised } \\
\text { to mould laged } \\
4-13 \text { years) } \\
\text { Follow-up: } 1 \text { year }\end{array}$ \\
\hline $\begin{array}{l}\text { BunDY, Western } \\
\text { Massachusetts } \\
\text { and Connecticut, } \\
\text { USA [106] }\end{array}$ & $\begin{array}{l}225 \text { children with } \\
\text { asthma (6-12 years } \\
\text { old) } \\
\text { Follow-up: } 2 \text { weeks }\end{array}$ \\
\hline
\end{tabular}

PongRaCIC, the
Inner-City
Asthma Study:
USA
[107]

\section{Wu, USA [32]}

\section{Gent, Western \\ Massachusetts and Connecticut, USA [108]}

469 children with mild to severe asthma and at least one positive SPT to mould laged 5-

11 years)

Follow-up: 2 years

395 children with mild-to-moderate persistent asthma CAMP study (aged 5-12 years) Follow-up: 6 months and 3 years or before in case of moving

1233 school-aged children with asthma laged $5-10$ years)
At baseline: positive response to a question on visible mould in the past 2 years

Every month: indoor air: MAS-100 Eco $100 \mathrm{~L} \cdot \mathrm{min}^{-1}$ Culture $\mathrm{CFU} \cdot \mathrm{m}^{-3}$ : Cladosporium, Penicillium, Aspergillus, Alternaria and others (undefined or $>1 \%$ ) At baseline: indoor air: Burkard $1 \mathrm{~min} 20 \mathrm{~L} \cdot \mathrm{min}^{-1}$ Culture and classification: $0 \mathrm{CFU} \cdot \mathrm{m}^{-3}, 1-499 \mathrm{CFU} \cdot \mathrm{m}^{-3}$, 500-999 CFU.m ${ }^{-3},>1000$ $\mathrm{CFU} \cdot \mathrm{m}^{-3}$, Cladosporium, Alternaria, Penicillium or Aspergillus Follow-up: 1 month
At baseline and at the first follow-up (6 months): dust measurements on floor (main living room, bedrooms and kitchen) and on child's bed

Vacuum cleaner equipped with a filter (Douglas ReadiVac model): 2 min for each zone of different surfaces

Culture and classification:

high mould dust exposure: $>25000 \mathrm{CFU} \cdot \mathrm{g}^{-1}$ of house dust

At baseline: indoor air:

Burkard $1 \mathrm{~min} 20 \mathrm{~L} \cdot \mathrm{min}^{-1}$, culture: $\mathrm{CFU} \cdot \mathrm{m}^{-3}$

Dust measurements on floor and furniture in the main living room

Blood allergens: mould, mites, cat, dog $\left(\mu \mathrm{g} \cdot \mathrm{g}^{-1}\right)$ and cockroaches $\left(U \cdot g^{-1}\right)$ cough), drugs and severity

\section{Daily variability of peak flow Daily symptoms: wheezing, cough, BHR at follow-up}

No association between mould exposure and symptoms

In exposed children: increased peak flow variability: $+2.70 \%$ (95\% Cl 0.92-4.47, p=0.003), and higher BHR: aOR: 3.95 (1.82-8.57)

Daily variability of peak flow: morning and evening

Daily symptoms (rhinitis and asthma scores)

No association between mean exposure to mould 337.5

$\mathrm{CFU} \cdot \mathrm{m}^{-3}$ ) and daily variability of peak flow or symptoms

Daily variability of peak flow: three series of measurements morning and evening performed by children

Daily symptoms Iwheezing, cough and nocturnal

symptoms), drugs reported by the mother

Call report every 2 months: max number of days (in 2 weeks) with symptoms lwheezing, cough, chest tightness, awakening due to asthma or play activities stopped because of asthmal Number of unplanned visits to hospital or EV in the past 2 months

Severe asthma exacerbations Hospitalisations or urgent care visits during the 4 years of follow-up (report every 4 months)

Polymorphisms (SNPs) in chitinase genes

Daily symptoms (wheezing, (five levels)

Allergic sensitisation: allergens and $\lg E$
No association between mould exposure and symptoms Associations between

Penicillium 10 versus detectable) and peak flow variability of $>18.5 \%$ (75th percentile) aOR $2.39(95 \% \mathrm{Cl}$ 1.19-4.81)

Association between 10 -fold increase in Penicillium level and increased number of days with symptoms: 1.19 days per 2 weeks, $p<0.03$

Association between indoor mould and exacerbations and EV:

aOR $1.22(95 \%$ Cl 1.05-1.43) and $1.13(1.01-1.26)$

Association between Penicillium and EV: OR 1.15 (1.05-1.27) lall children), and 1.11 (1.03-1.20) in those SPT- for Penicillium $24 \%$ ( $n=95$ ) had high mould dust exposure

Number of urgent care visits increased with high mould dust exposure in children with genetic polymorphisms (rs2486953, rs4950936 and rs1417149) in the CHIT1 gene

In sensitised children: associations between Penicillium and risk of wheezing: aOR $2.12(95 \% \mathrm{Cl}$ 1.12-4.04), cough: 2.01 (1.053.85) and asthma severity score: 1.99 (1.06-3.72) 
TABLE 2 Continued

$\begin{aligned} & \text { First author, } \\ & \text { location }\end{aligned}$
[ref.]

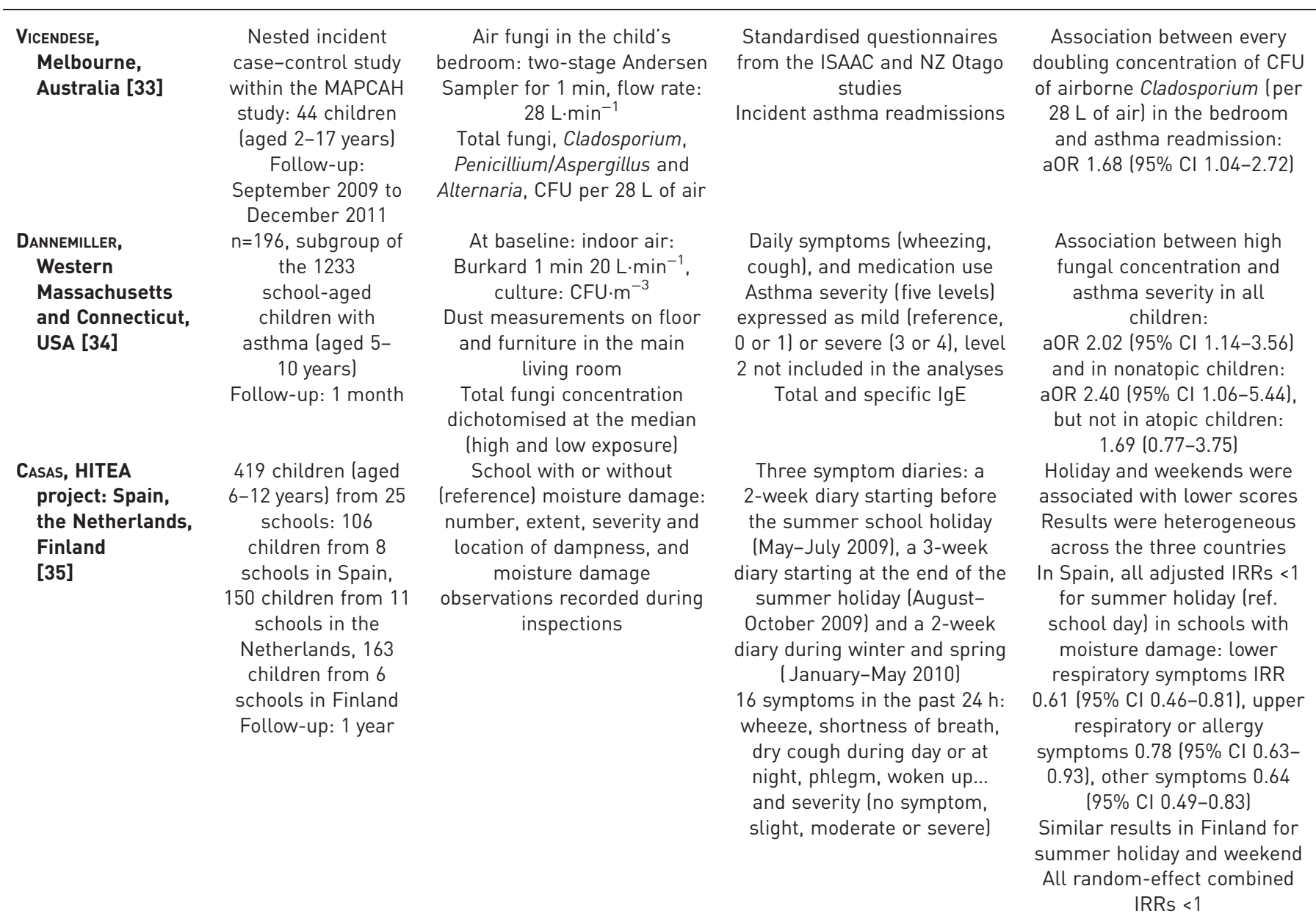

HITEA: Health Effects of Indoor Pollutants: Integrating Microbial, Toxicological and Epidemiological Approaches; BHR: bronchial hyperresponsiveness; aOR: adjusted odds ratio; EV: emergency visit; SPT: skin prick test; SNP: single nucleotide polymorphism; Ig: immunoglobulin; MAPCAH: Melbourne Air Pollen Children and Adolescent Health; ISAAC: International Study of Asthma and Allergies in Childhood; IRR: incidence rate ratio.

combined exposure to mould and wall-to-wall carpet in the workplace was associated with a significant increased risk of incident asthma.

In the general population, the analysis of data on dampness retrospectively collected as part of the Respiratory Health in Northern Europe (RHINE) follow-up showed that subjects living in damp homes had a higher risk to develop respiratory symptoms, compared to those living in dry homes [37]. Conversely, the remission of respiratory symptoms was less common in damp homes. As regards asthma, no significant association was observed despite the large sample size and relatively high number of new-onset asthma cases. Questions specifically focusing on mould exposure were only asked at follow-up. The cross-sectional analysis of these data showed a significant relationship between asthma and the presence of visible mould.

Analyses of the ECRHS population-based study of young adults considered "dampness" and "mould" scores calculated as the number of positive answers to the presence of "mould or mildew on any surface inside the home" ever and in the past 12 months both at baseline and follow-up ( 9 years after baseline) $[38,39]$. In addition, 3118 homes were inspected at follow-up for the presence of dampness and mould. Dampness and mould were common at baseline and follow-up ( $\sim 10 \%$ of the sample reported water damage and $\sim 16 \%$ reported visible mould in the past 12 months). It is noteworthy that the dampness 
score and the mould score showed relatively poor agreement. No significant relationship was found between reported or observed mould exposure and lung function decline [38]. However, other aspects of building dampness (such as water leakage or damp spots) were associated with accelerated lung function decline, but only in females. The reasons why a stronger effect was observed in females are unclear. A greater susceptibility or a longer exposure time in the dwelling for females is speculated. Another study of the same cohort was focused on the risk of asthma onset in subjects without asthma or respiratory symptoms at baseline [39]. There was an excess risk of new asthma onset in subjects reporting mould indoor in the past 12 months at baseline, although no significant relationship was found when considering specifically mould (ever) in the bedroom or in the living room at baseline. A dose-response effect was observed when the score combining exposure at baseline and follow-up was used. No significant interaction by sex was observed, apart for mould exposure in the living room which showed a significant effect only in females. Some heterogeneity was observed between centres. Therefore, this study is one of the first to show a significant relationship between mould exposure in the dwelling and subsequent asthma onset, and to report a dose-response effect. However, the score used for the dose-response relationship combined data from baseline and follow-up.

To summarise the four longitudinal studies identified in our literature review: one study showed an effect of the combined exposure to wall-to-wall carpets and to mould at work, but found no significant effect of visible mould or mould odour at home [36]; one study showed an excess incidence and less frequent remission of respiratory symptoms in individuals living in damp homes, but no significant association with asthma [37]; one study [39] reported a significant relationship between mould exposure in the dwelling and subsequent asthma onset; and the final study showed a significant relationship between lung function decline and various aspects of building dampness, but not with mould exposure when considered specifically [38].

In conclusion, given the small number of longitudinal studies with a particular focus on mould exposure, and the lack of consistent findings, there is limited evidence on the effect of mould exposure on asthma onset in adults from the general population. Further studies are clearly warranted.

\section{Longitudinal studies on occupational asthma related to working in mouldy buildings}

Studies on respiratory health in adults working in damp buildings provide additional evidence for the existence of associations between mould exposure and the incidence and morbidity of asthma in adults (table 3).

In Finland, JАAкKоLA et al. [40] had already shown that the risk of incident asthma was related to the presence of visible mould and/or mould odour in the workplace. In a later study a relationship was demonstrated between incident asthma and the combined presence of mould problems and wall-to-wall carpet in the workplace [36]. In this country, indoor moulds from water-damaged buildings have become the most important causative agents of occupational asthma since 2001 [41]. In compliance with compensation policy, most cases referred to the Finnish Institute of Occupational Health are confirmed objectively by specific inhalation challenge tests with mould extracts.

In a first study (table 3), Karvala et al. [42] followed 136 patients with "probable" occupational asthma. After 6 months of follow-up, 42\% were no longer working, while none of the 13 still exposed reported improvement of symptoms. In a second study [43], 483 patients with asthma-like symptoms related to damp workplaces, but without objective evidence of asthma at inclusion, were followed-up for 3-12 years. The risk of developing asthma was 4.6 times higher in patients still exposed. Additional studies of workers with mould-induced asthma further evidenced impaired quality of life, work disability and a high rate of work withdrawal $[44,45]$. In a study of US employees in a water-damaged office, PARK et al. [46] showed a significant association between asthma with post-occupancy onset and the levels of exposure to mould, especially hydrophilic fungi. In another study [47], the same authors found a dramatic increase in the risk of developing building-related asthma symptoms (OR 7.4, 95\% CI 2.8-19.9) in individuals with a high level of both fungal exposure and building-related rhinosinusitis at inclusion. Of note, only the initial mould exposure, but not subsequent exposures, was a significant predictor of building-related asthma symptoms, which suggests that it might be more relevant to understand the historical exposure to dampness rather than focusing on recent exposure. The authors proposed that building-related rhinosinusitis should be considered as a warning for increased risk of developing asthma symptoms and prompt identification of mould problems and timely effective remediation.

In conclusion, these prospective studies provide sufficient evidence of an association between indoor mould exposure at work and the development of asthma, but insufficient evidence for a causal relationship, with further prospective studies in other countries being needed. 
TABLE 3 Longitudinal studies on occupational asthma related to working in mouldy buildings

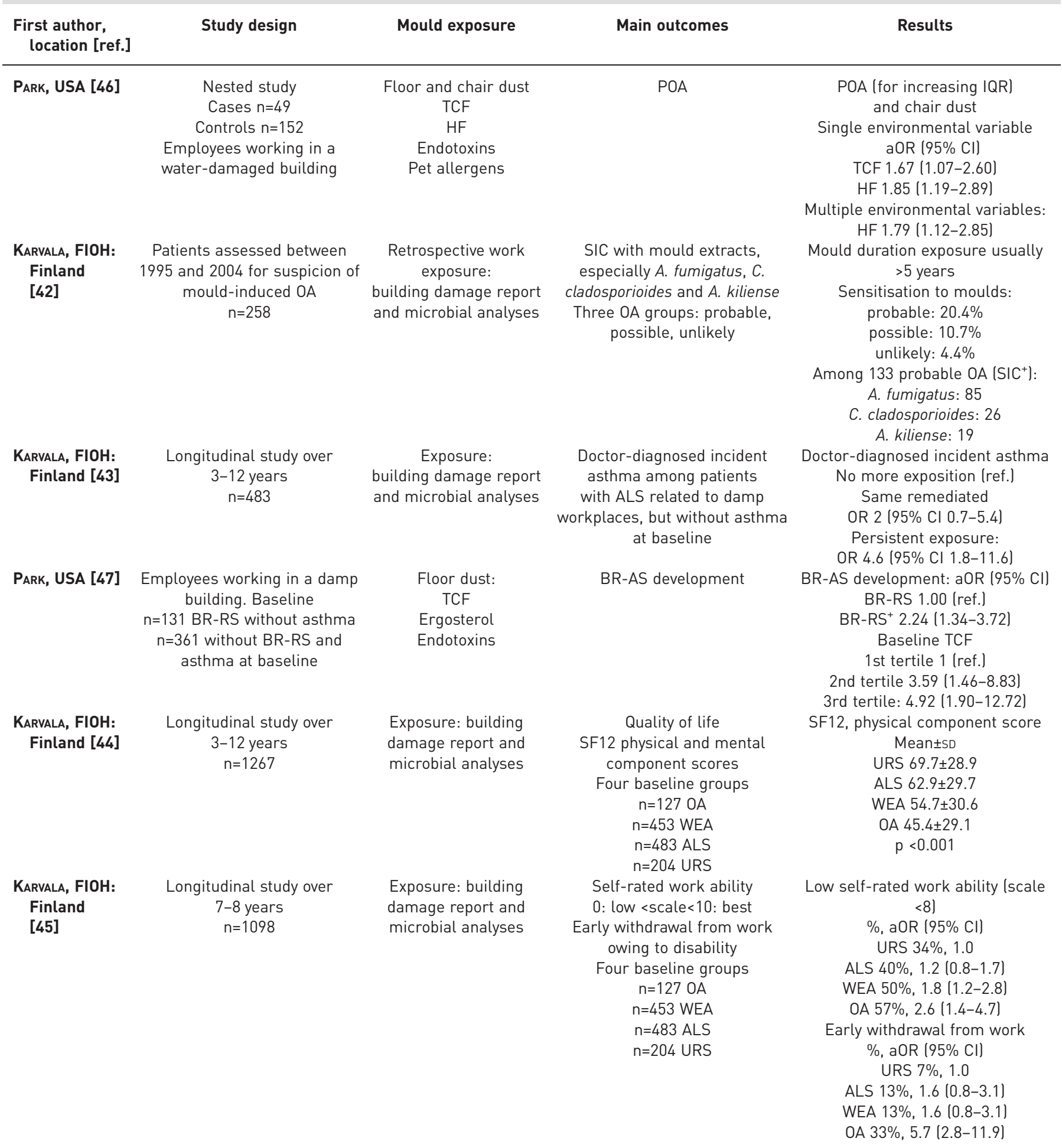

FIOH: Finnish Institute of Occupational Health; TCF: total culturable fungi; HF: hydrophilic fungi; POA: post-occupancy asthma; IQR: interquartile range; aOR: adjusted odds ratio; OA: occupational asthma; SIC: specific inhalation challenge; A. fumigatus: Aspergillus fumigatus; C. cladosporioides: Cladosporium cladosporioides; A. kiliense: Acremonium kiliense; ALS: asthma-like symptoms; BR: building-related; RS: rhinosinusitis; AS: asthma symptoms, WEA: work-exacerbated asthma; URS: upper respiratory symptoms; SF12: 12-item short form survey. 
Recent reviews, meta-analyses and longitudinal studies on rhinitis

Several meta-analyses have covered the relationships between mould or dampness exposure and rhinitis (table 4). In 2007, combining data from 13 cross-sectional and longitudinal studies, FISK et al. [15] showed a significant relationship between exposure to mould and/or dampness and upper respiratory tract symptoms, with no evidence of publication bias. In the Pollution and the Young (PATY) consortium [5], consisting of seven cross-sectional studies in children from different areas, visible mould was associated with an increased risk of hay fever.

In their review, Mendell et al. [6] concluded that there was sufficient evidence for the existence of an association between home dampness or mould exposure and risk of upper respiratory tract symptoms and allergic rhinitis, but insufficient evidence of a causal relationship, because of insufficient evidence with regards to causal microbial exposure or dose-response relationships to define "safe" levels of exposure.

Tischer et al. [7] performed a systematic review in children, considering more specific criteria for mould exposure and giving more weight to longitudinal studies. However, their meta-analysis included both cross-sectional and longitudinal studies. They concluded that exposure to visible mould was associated with an increased risk of allergic rhinitis in children, and that the results were consistent with the evaluation of causation according to Hill's criteria. However, the authors also reported findings showing a tendency towards a lower risk of allergic health outcomes in children exposed to mould-derived components [7]. In addition, they found some suggestion of moderate publication bias.

In another study, pooling data from six European birth cohorts, Tischer et al. [8] showed that exposure to visible mould and/or dampness during the first 2 years of life was associated with an increased risk of allergic rhinitis later in childhood. It is the largest longitudinal study to show relationships between exposure to dampness and the development of allergic rhinitis. However, its focus was not specifically on mould exposure.

A more recent meta-analysis by JAAKKOLA et al. [48] included findings published up to August 2012. The authors considered various criteria to define mould exposure. For allergic rhinitis, the highest effect estimate was obtained when the exposure concerned mould odour. A significant and relatively homogeneous association was observed with visible mould. However, most of the studies were cross-sectional. Because the risks of rhinitis and allergic rhinitis were similarly increased, the authors suggested that other mechanisms than allergic ones could also play a role.

Few longitudinal studies have focused on mould exposure (table 4), and only two were not referenced in the systematic reviews. In the Boston birth cohort [28], children with higher levels of Aspergillus in bedroom floor dust in infancy were more likely to develop rhinitis, but no association was observed for total fungi. In the BAMSE (Barn/Child Allergy Milieu Stockholm Epidemiology) cohort, visible mould and mould odour in infancy were associated with an increased risk of rhinitis up to the age of 16 years [26]. It is noteworthy that exposure to any mould or dampness indicator during infancy was associated with a significant increased risk of nonallergic rhinitis and with a nonsignificant decreased risk of allergic rhinitis at age 16 years.

To summarise, systematic reviews and meta-analyses published since 2006 on the relationships between mould exposure and allergic rhinitis provide sufficient evidence of an association, with an odds-ratio generally $>1.35$ (table 4). However, most of the studies that specifically focused on exposure to mould are cross-sectional studies, while the longitudinal studies considered "exposure to mould and/or dampness". Conversely, some studies have suggested there is a possible decreased risk of allergic rhinitis in individuals exposed to mould-derived components. Moreover, the few longitudinal studies to date do not provide consistent evidence. Further longitudinal studies are needed to specifically study the associations between mould exposure and allergic rhinitis, nonallergic rhinitis and rhinitis severity to yield conclusive evidence of the differential effect of the various fungal components related to home dampness.

\section{Discussion}

We reviewed data from literature published between January 2006 and November 2017 on the associations between mould exposure and asthma and rhinitis by studying children and adults separately. New findings extended the conclusions of the IOM and WHO reports (table E3). In children, we concluded for the first time that there was a sufficient evidence of a causal relationship between exposure to indoor moulds and the development and exacerbation of asthma. In adults, we concluded that there was a sufficient evidence of an association for asthma in relation to work in a mouldy and damp building, and a limited level of evidence in the general population due to insufficient data. Based on the findings from systematic reviews and meta-analyses, we concluded for the first time on a sufficient level of evidence for an association for allergic rhinitis. This review highlights the areas where further studies are still needed. 
TABLE 4 Mould exposure and rhinitis: findings from meta-analyses, longitudinal studies and birth cohorts

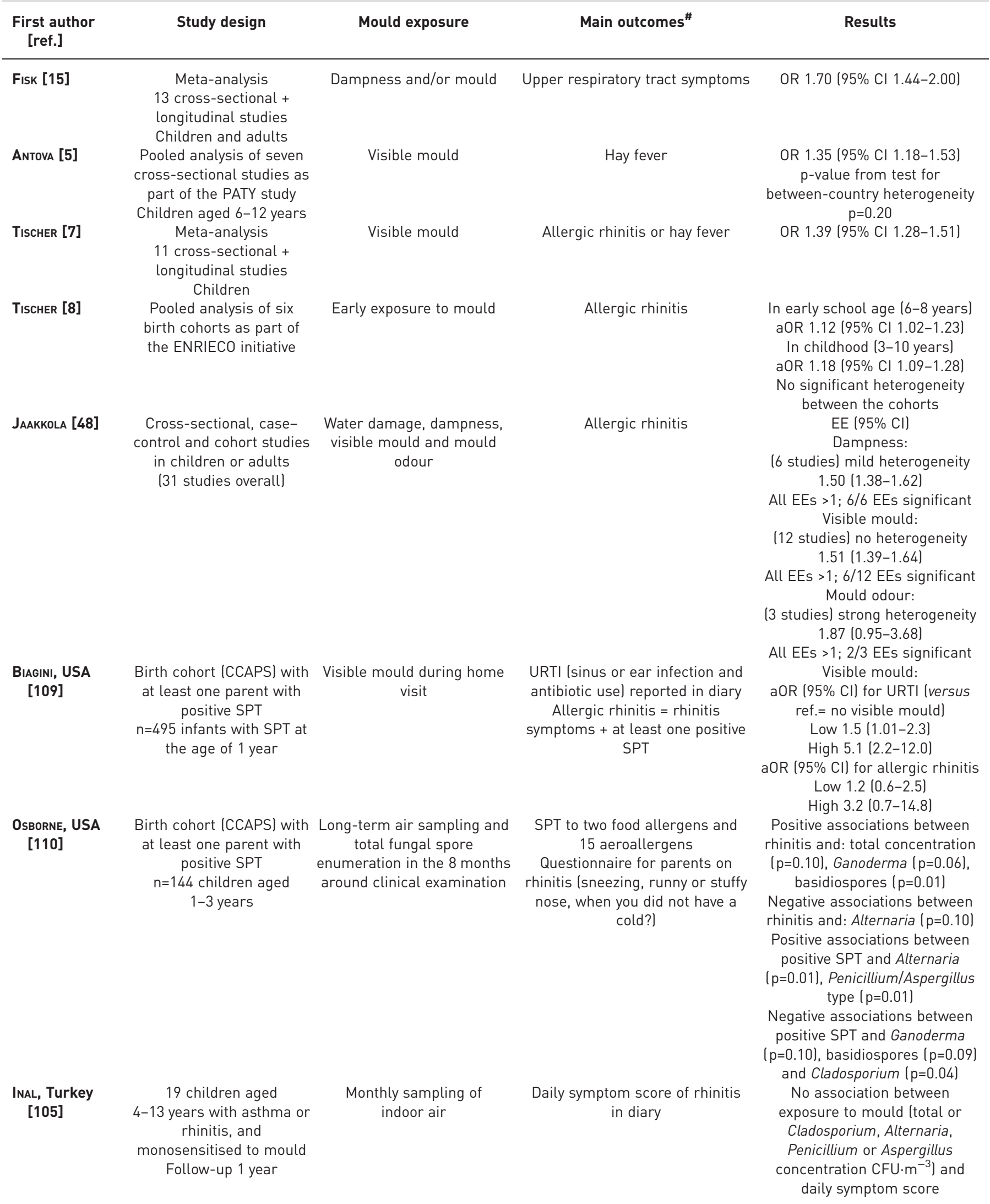


TABLE 4 Continued

\begin{tabular}{ccc}
$\begin{array}{c}\text { First author } \\
\text { [ref.] }\end{array}$ & Study design & Mould exposure \\
\hline $\begin{array}{c}\text { JAAKKOLA, } \\
\text { Finland [111] }\end{array}$ & $\begin{array}{c}\text { Population-based } \\
\text { prospective cohort } \\
n=1863 \text { children aged } \\
1-7 \text { years, free of allergic } \\
\text { rhinitis at baseline } \\
\text { in 1991 } \\
\text { (n=246 incident cases) }\end{array}$ & $\begin{array}{c}\text { Visible mould, wet spots, } \\
\text { water damage and indicator } \\
\text { of "any" exposure }\end{array}$ \\
\end{tabular}

Main outcomes ${ }^{\#} \quad$ Results

\section{Development of allergic rhinitis (incident cases) (history of or current physician-diagnosed allergic rhinitis during the 6-year follow-up period]}

BeHвod, USA [28] Prospective birth cohort 408 children with family history of allergic disease or asthma followed-up to age 13 years

\section{Thacher, Sweden Birth cohort (BAMSE) [26] $n=3798$ children with follow-up data at age 16 years}

Parental report of home dampness and culturable fungi in bedroom air and dust, and in outdoor air when children were aged 2-3 months Indoor air: Burkard DG18: $1 \mathrm{~min} 45 \mathrm{~L} \cdot \mathrm{min}^{-1}$ Culture: identification of fungal genus

Parental report when the child was 2 months, of mould odour ever in the home, visible mould in the home in the past year or moisture damage in the home
Symptoms/disease onset from birth to age 13 years

For rhinitis: parental report of physician-diagnosed hay fever and nasal symptoms (runny nose)

Mould sensitisation status tested at ages 7 and 13 years (in $n=285$ )

Rhinitis: eye or nose symptoms following exposure to allergens in the past 12 months and/or a doctor's diagnosis of allergic rhinitis (+/- positive Phadiatop test) at age 16 years
OR for allergic rhinitis incidence (compared to $r e f=$ no exposure)

Visible mould at baseline 1.06 (0.51-2.21):

at follow-up 1.98 (1.32-2.99)

Mould odour at baseline 0.94 (0.36-2.45):

at follow-up 1.45 (0.89-2.37)

Any exposure at baseline 1.55 (1.10-2.18);

at follow-up 1.62 (1.21-2.18);

at baseline and follow-up 1.96 (1.29-2.98)

HR (95\% CI) for rhinitis onset Home dampness 1.11 (0.73-1.68)

Dust (bedroom floor)

Alternaria 0.79 (0.51-1.22)

Cladosporium 0.91 (0.77-1.08)

Aspergillus 1.39 (1.11-1.74)

Penicillium 1.04 (0.89-1.21)

Yeasts 1.06 (0.92-1.22)

Nonsporulating fungi 1.05 (0.88-1.25)

Measures in indoor air: no significant association observed OR $(95 \% \mathrm{Cl})$ for rhinitis at age 16 years

Visible mould 1.28 (1.04-1.58)

Mould odour 1.29 (1.03-1.62)

Any mould or dampness

indicator for nonallergic rhinitis $1.41(1.03-1.93)$;

allergic rhinitis 0.88 (0.74-1.05)

PATY: Pollution and the Young; ENRIECO: Environmental Health Risks in European Birth Cohorts; aOR: adjusted odds ratio; EE: effect estimate; CCAPS: Cincinnati Childhood Allergy and Air Pollution Study; SPT: skin prick test; URTI: upper respiratory tract infection; BAMSE: Barn/Child Allergy Milieu Stockholm Epidemiology. " : other outcomes are considered in the articles cited.

We focused on longitudinal studies, whose design allows the ascertainment of temporality by assessing exposure before the onset of the disease and which are less subject to biases encountered in cross-sectional studies. In addition, we reviewed the results of seven meta-analyses that included cross-sectional studies. This approach provides a broad spectrum of asthma definition, based or not on standardised and validated questionnaires, including self- (or parent-) reports of wheezing, especially in children, in whom asthma is difficult to diagnose, and self-reports of asthma symptoms or doctor-diagnosed asthma. We limited our review to respiratory symptoms and have not included specific terms for identifying studies using biomarkers in our search. Studies using biomarkers provide evidence of the effect of mould in the inflammatory response, and are very useful in identifying underlying pathways. However, these studies were not included in the present review which summarises the effect on asthma incidence and exacerbation at the population level in children and adults, and on rhinitis. Biomarker measurements are valuable complements to symptom registrations, rather than recommended as core asthma outcomes [49]. Their measurements are mostly reported in cross-sectional studies, and more rarely in longitudinal studies on large sample sizes; no consensus exists on the biomarker to use [50]; their added value in the management of asthma is strongly associated with specific asthma profile [51]; and omics technologies remain at an early stage [52].

Our review focused on exposure to moulds alone or in association with dampness, but did not include studies considering dampness alone. Our search focused on mould and fungi as keywords, without 
including specifically microbial, moisture or bio-contaminant. Indeed, mould and dampness exposures are often concomitant, leading to increased fungal growth and related factors, such as fungal spores, hyphae, fragments [53], microbial volatile organic compounds [54,55], mycotoxins [56], house dust mite allergens [57] and endotoxins [58-60]. Endotoxins can have both additional and synergistic effects on respiratory health [46]. It is possible that inhalation of these agents, singly or in unknown combinations, induces inflammatory [61] and/or immunosuppression responses that result in the development or exacerbation of respiratory illnesses. One of the current challenges for researchers is to understand how the interactions between fungi and these other micro-organisms will impact health [62]. Mould exposure was defined either qualitatively or quantitatively, which includes a wide range of exposures. In the current state of knowledge concerning dose-response relationships, it is not possible to define a threshold below which no effect on health is expected for the general population $[11,62]$. On the one hand, there is a wide range of exposure indicators linked to health effects, which has given rise to conflicting results, and on the other, it is difficult to identify the mechanisms of action involved and the underlying susceptibility of individuals in the case of respiratory symptoms (in particular immuno-allergic predispositions). Nevertheless, we consistently observed some associations, and posit the existence of a causal relationship for the development and exacerbation of asthma in children.

Assessing mould exposure is difficult and complex, and the analysis of samples of air and dust varies across studies and is based on different methods [62]. In many studies, fungal exposure is often reduced to a qualitative measurement such as "visible mould". Future research should include simple and validated metrics of mould and dampness with inclusion of mould odour (reflecting hidden moulds) and study on dose-response effects in order to provide health protective thresholds [63]. More recent sampling and measurement methods should be validated and developed in future years. Usual collecting mould air sampling is very short (1-5 $\mathrm{min}$ ) in order to avoid excessively high density of colonies on Petri dishes, which makes counting impossible. Thus, the representativeness of these short sampling times is disputable, due to limited repeatability [64]. Electrostatic dust collectors applied for extended periods of time can overcome these caveats because they are indicative of longer time exposure [65]. However, mould colony counting on Petri dishes are limited by definition to those that will grow on the media selected. The culturable fungi might be unrelated to a specific health effect, even if these methods inform on the global mould contamination of a room. Real-time qPCR can detect nonculturable fungi or nonviable fungal spores that may have health impacts [66]. The ERMI scale measures the mould burden of a large number of fungal species and is widely used in current research. Initially developed in the United States [67], it was remodelled for use in other countries, such as Finland [68]. One challenge with qPCR is to decide which of the relevant assays should be applied, as this method is selective in the sense that only moulds that are targeted by the assays will be detected [62]. If nonselective assays, often described as "panfungal", are used, the risk is to amplify the most frequent fungal species because of the competitive nature of the amplification process, and not the most clinically relevant [66]. Metataxonomic and metagenomic approaches are still under evaluation for investigating complex environmental samples [69]. These new techniques should be confronted to qualitative studies, and demonstrate they are more valid exposure tools than observed mould/dampness exposure.

Mould exposure is one piece of a larger exposure, including co-exposure to fungi and bacteria. There is increasing evidence that microbial or fungal diversity might show a stronger effect than the level of any single component $[30,70]$. One hypothesis is that the increase in the prevalence of asthma observed in the last few decades is attributable in part to declining exposure to environmental micro-organisms [70], and the "hygiene hypothesis" goes some way to explain this global change [71]. Indeed, low prevalence of allergic diseases and inverse associations between exposure to fungi and asthma development have been observed in children living on traditional farms, where there is a high diversity of fungi and bacteria, and intense and sustained exposure to microbes [72-74]. Last, but not least, the role of outdoor exposure to pollutants such as fungal spores [75] and pollen in respiratory health [76] was not included in the present review. Future epidemiological studies should assess as best as possible the exposure to moulds, but also collect co-exposures in order to identify exposure profiles through clustering methods as done in the study by Madureira et al. [77], and in the Elfe cohort study [78].

In addition to co-exposures, various factors related to the built environment can contribute to variation in fungal diversity and load such as adequate heating, opening windows or use of extractor [79], property type and age and the extent of household insulation [80]. Differences between the built environment [81], geographic areas and/or climates [82] and factors related to the behaviour of occupants [83] or specific to the population under study, such as sex, age, socioeconomic status, atopy, rhinitis, health status, genetic susceptibility and gene by mould exposure interaction [21, 84, 85] can also modify the associations. The epidemiological studies reviewed in the present article tried, as best as possible, to take into account these confounders or effect modifiers. In many studies, the participants were mono- or polysensitised or with a 
family history of allergic diseases or asthma. Overall, although investigating the associations between indoor fungal exposures and respiratory health is highly complex [86], all these factors should be taken into account in future studies. Results from longitudinal epidemiological studies in children without sensitisation or family history of allergic diseases or asthma would be a valuable contribution to ongoing research.

Several biological mechanisms have been proposed to support the role of mould exposure in respiratory health [87] involving allergic and nonallergic mechanisms [88, 89], such as toxicity from mould by-products [90]. Interestingly, a recent paper by ZHANG et al. [91] found that fungi have potent immunomodulatory properties, independent of fungal sensitisation, and promote progression of allergic asthma to severe steroid-resistant asthma characterised by mixed T-helper type 2 or 17 responses. The measurement of antibodies to specific mould has scientific merit but the precise recognition of species-specific IgE sensitisation to fungal allergens remains challenging [92]. In the near future, the use of recombinant mould allergens should improve the diagnosis of fungal allergy [93]. Before having a clear framework of the biological mechanisms, and hence the appropriate medication or treatment, another way to tackle the problem is to remove exposure to mould [94]. A Cochrane review found very low- to moderate-quality evidence that remediation of dampness and mould in homes decreases asthma-related symptoms [95]. More recently, LE CANN et al. [96] performed a systematic review of home environmental interventions implemented to improve health of patients with respiratory diseases, including measures to reduce mould exposure. Reduced levels of fungal spores were observed in some studies after home interventions, particularly in single-family homes where the baseline levels of fungal exposure were considerably higher than in apartments. Some studies showed a reduction in asthma morbidity after interventions aiming at reducing mould exposure in asthmatic children living in homes with documented mould problems. However, other studies showed limited or no significant change in respiratory outcomes after interventions $[96,97]$. New randomised controlled trials with careful measurements of exposure and respiratory outcomes are needed to document the causality and effectiveness of real-world environmental interventions in mouldy buildings.

In conclusion, we reviewed the literature between 2006 and 2017 on the associations between exposure to moulds, alone or in combination with dampness and asthma and rhinitis. Longitudinal epidemiological data in children were analysed separately from those of adults. New findings extend the previous conclusions established in 2007. In particular, sufficient evidence of a causal relationship for asthma development and exacerbation in children, and sufficient evidence of an association with allergic rhinitis were found, but additional evidences are needed from longitudinal studies among adults, especially population-based studies.

Acknowledgements: The members of the ANSES "Moisissures dans le bâti" working group are as follows: S. Roussel (CHU, Besançon, France), C. Ashan-Leygonie (Université Lyon 2, Lyon, France), V. Bex (SPSE, Paris, France), S. Bretagne (APHP, Paris, France), D. Caillaud (CHU, Clermont-Ferrand, France), A.C. Colleville (SPF, Saint-Maurice, France), E. Frealle (CHRU, Lille, France), S. Ginestet (INSA, Toulouse, France), L. Lecoq (IMT, Nantes, France), B. Leynaert (INSERM, Paris, France), R. Nadif (INSERM, Villejuif, France), I. Oswald (INRA, Toulouse, France), G. Reboux (CHU, Besançon, France), and T. Bayeux (ANSES), C. Fourneau (ANSES) and M. Keirsbulck (ANSES).

Author contributions: D. Caillaud, B. Leynaert and R. Nadif were members and M. Keirsbulck was the coordinator of the ANSES working group. All authors wrote the paper, participated in revision of the manuscript and gave approval of the final version.

Conflict of interest: None declared.

\section{References}

1 Beasley R, Semprini A, Mitchell EA. Risk factors for asthma: is prevention possible? Lancet 2015; 386: 1075-1085.

2 Mudarri DH. Valuing the economic costs of allergic rhinitis, acute bronchitis, and asthma from exposure to indoor dampness and mold in the US. J Environ Public Health 2016; 2016: 2386596.

3 Institute of Medicine. Damp Indoor Spaces and Health. Washington, DC, National Academies Press, 2004.

4 World Health Organization (WHO). WHO Guidelines for Indoor Air Quality: Dampness and Mould. Geneva, WHO, 2009.

5 Antova T, Pattenden S, Brunekreef B, et al. Exposure to indoor mould and children's respiratory health in the PATY study. J Epidemiol Community Health 2008; 62: 708-714.

6 Mendell MJ, Mirer AG, Cheung K, et al. Respiratory and allergic health effects of dampness, mold, and dampness-related agents: a review of the epidemiologic evidence. Environ Health Perspect 2011; 119: 748-756.

7 Tischer C, Chen CM, Heinrich J. Association between domestic mould and mould components, and asthma and allergy in children: a systematic review. Eur Respir J 2011; 38: 812-824.

8 Tischer CG, Hohmann C, Thiering E, et al. Meta-analysis of mould and dampness exposure on asthma and allergy in eight European birth cohorts: an ENRIECO initiative. Allergy 2011; 66: 1570-1579.

9 Quansah R, Jaakkola MS, Hugg TT, et al. Residential dampness and molds and the risk of developing asthma: a systematic review and meta-analysis. PLoS One 2012; 7: e47526. 
Dick S, Friend A, Dynes K, et al. A systematic review of associations between environmental exposures and development of asthma in children aged up to 9 years. BMJ Open 2014; 4: e006554.

Agence Nationale de Sécurité Sanitaire - Alimentation, Environnement et Travail (ANSES). Moisissures dans le Bâti. Avis et Rapport d'Expertise Collective. [Mould in Buildings: Scientific Expert Assessment]. ANSES, Maisons-Alfort, 2016. www.anses.fr/fr/system/files/AIR2014SA0016Ra.pdf

Agence Nationale de Sécurité Sanitaire - Alimentation, Environnement et Travail (ANSES). Revised Opinion of the French Agency for Food, Environmental and Occupational Health and Safety on Mould in Buildings, Maisons-Alfort, 2016. www.anses.fr/en/system/files/AIR2014SA0016EN.pdf

Conseil Supérieur d'Hygiene Publique de France. Contaminations Fongiques en Milieux Intérieurs. [Fungal Contamination in Indoor Environments.] 2006. http://solidarites-sante.gouv.fr/IMG/pdf/Contaminations_fongiques_ en_milieux_interieurs.pdf

Hill AB. The environment and disease: association or causation? Proc R Soc Med 1965; 58: 295-300.

Fisk WJ, Lei-Gomez Q, Mendell MJ. Meta-analyses of the associations of respiratory health effects with dampness and mold in homes. Indoor Air 2007; 17: 284-296.

Kanchongkittiphon W, Mendell MJ, Gaffin JM, et al. Indoor environmental exposures and exacerbation of asthma: an update to the 2000 review by the Institute of Medicine. Environ Health Perspect 2015; 123: 6-20.

Sharpe RA, Bearman N, Thornton CR, et al. Indoor fungal diversity and asthma: a meta-analysis and systematic review of risk factors. J Allergy Clin Immunol 2015; 135: 110-122.

Vesper S, Wymer L. The relationship between environmental relative moldiness index values and asthma. Int $J$ Hyg Environ Health 2016; 219: 233-238.

Reponen T, Vesper S, Levin L, et al. High environmental relative moldiness index during infancy as a predictor of asthma at 7 years of age. Ann Allergy Asthma Immunol 2011; 107: 120-126.

Pei Zam H, Emilia Z, Karmegam K, et al. Dampness and mold exposure in buildings as a risk factor for health effects. Mal J Pub Health Medicine 2017; 1 (special issue): 28-40.

Hwang BF, Liu IP, Huang TP. Gene-environment interaction between interleukin-4 promoter and molds in childhood asthma. Ann Epidemiol 2012; 22: 250-256.

Shorter C, Täubel M, Pierse N, et al. Objective assessment of domestic mold contamination using quantitative PCR. J Allergy Clin Immunol 2016; 137: 622-624.

Zhou C, Baiz N, Zhang T, et al. Modifiable exposures to air pollutants related to asthma phenotypes in the first year of life in children of the EDEN mother-child cohort study. BMC Public Health 2013; 13 : 506.

Wen HJ, Chiang TL, Lin SJ, et al. Predicting risk for childhood asthma by pre-pregnancy, perinatal, and postnatal factors. Pediatr Allergy Immunol 2015; 26: 272-279.

Karvonen AM, Hyvärinen A, Korppi M, et al. Moisture damage and asthma: a birth cohort study. Pediatrics 2015; 135: e598-e606.

Thacher JD, Gruzieva O, Pershagen G, et al. Mold and dampness exposure and allergic outcomes from birth to adolescence: data from the BAMSE cohort. Allergy 2017; 72: 967-974.

Behbod B, Sordillo JE, Hoffman EB, et al. Wheeze in infancy: protection associated with yeasts in house dust contrasts with increased risk associated with yeasts in indoor air and other fungal taxa. Allergy 2013; 68: $1410-1418$.

Behbod B, Sordillo JE, Hoffman EB, et al. Asthma and allergy development: contrasting influences of yeasts and other fungal exposures. Clin Exp Allergy 2015; 45: 154-163.

Rosenbaum PF, Crawford JA, Anagnost SE, et al. Indoor airborne fungi and wheeze in the first year of life among a cohort of infants at risk for asthma. J Expo Sci Environ Epidemiol 2010; 20: 503-515.

Dannemiller KC, Mendell MJ, Macher JM, et al. Next-generation DNA sequencing reveals that low fungal diversity in house dust is associated with childhood asthma development. Indoor Air 2014; 24: 236-247.

Tischer C, Weikl F, Probst AJ, et al. Urban dust microbiome: impact on later atopy and wheezing. Environ Health Perspect 2016; 124: 1919-1923.

Wu AC, Lasky-Su J, Rogers CA, et al. Fungal exposure modulates the effect of polymorphisms of chitinases on emergency department visits and hospitalizations. Am J Respir Crit Care Med 2010; 182: 884-889.

repeat child asthma hospital admissions. J Asthma 2015; 52: 727-731. Dannemiller KC, Gent JF, Leaderer BP, et al. Indoor microbial communities: influence on asthma severity in atopic and nonatopic children. J Allergy Clin Immunol 2016; 138: 76-83.

Casas L, Espinosa A, Pekkanen J, et al. School attendance and daily respiratory symptoms in children: influence of moisture damage. Indoor Air 2017; 27: 303-310.

Jaakkola JJ, Ieromnimon A, Jaakkola MS. Interior surface materials and asthma in adults: a population-based incident case-control study. Am J Epidemiol 2006; 164: 742-749.

Gunnbjörnsdóttir MI, Franklin KA, Norbäck D, et al. Prevalence and incidence of respiratory symptoms in relation to indoor dampness: the RHINE study. Thorax 2006; 61: 221-225.

Norbäck D, Zock JP, Plana E, et al. Lung function decline in relation to mould and dampness in the home: the longitudinal European Community Respiratory Health Survey ECRHS II. Thorax 2011; 66: 396-401.

Norbäck D, Zock JP, Plana E, et al. Mould and dampness in dwelling places, and onset of asthma: the population-based cohort ECRHS. Occup Environ Med 2013; 70: 325-331.

Jaakkola MS, Nordman H, Piipari R, et al. Indoor dampness and molds and development of adult-onset asthma: a population-based incident case-control study. Environ Health Perspect 2002; 110: 543-547.

Piipari R, Keskinen H. Agents causing occupational asthma in Finland in 1986-2002: cow epithelium bypassed by moulds from moisture-damaged buildings. Clin Exp Allergy 2005; 35: 1632-1637.

Karvala K, Toskala E, Luukkonen R, et al. New-onset adult asthma in relation to damp and moldy workplaces. Int Arch Occup Environ Health 2010; 83: 855-865.

Karvala K, Toskala E, Luukkonen R, et al. Prolonged exposure to damp and moldy workplaces and new-onset asthma. Int Arch Occup Environ Health 2011; 84: 713-721.

Karvala K, Uitti J, Luukkonen R, et al. Quality of life of patients with asthma related to damp and moldy work environments. Scand J Work Environ Health 2013; 39: 96-105. 
Karvala K, Nordman H, Luukkonen R, et al. Asthma related to workplace dampness and impaired work ability Int Arch Occup Environ Health 2014; 87: 1-11.

46 Park JH, Cox-Ganser JM, Kreiss K, et al. Hydrophilic fungi and ergosterol associated with respiratory illness in a water-damaged building. Environ Health Perspect 2008; 116: 45-50.

47 Park JH, Kreiss K, Cox-Ganser JM. Rhinosinusitis and mold as risk factors for asthma symptoms in occupants of a water-damaged building. Indoor Air 2012; 22: 396-404.

48 Jaakkola MS, Quansah R, Hugg TT, et al. Association of indoor dampness and molds with rhinitis risk: a systematic review and meta-analysis. J Allergy Clin Immunol 2013; 132: 1099-1110.

49 Szefler SJ, Wenzel S, Brown R, et al. Asthma outcomes: biomarkers. J Allergy Clin Immunol 2012; 129: S9-S23.

50 Vijverberg SJ, Hilvering B, Raaijmakers JA, et al. Clinical utility of asthma biomarkers: from bench to bedside. Biologics 2013; 7: 199-210.

51 Casale TB. Biologics and biomarkers for asthma, urticaria, and nasal polyposis. J Allergy Clin Immunol 2017; 139: 1411-1421.

52 Kelly RS, Dahlin A, McGeachie MJ, et al. Asthma metabolomics and the potential for integrative omics in research and the clinic. Chest 2017; 151: 262-277.

53 Reponen T, Seo SC, Grimsley F, et al. Fungal fragments in moldy houses: a field study in homes in New Orleans and Southern Ohio. Atmos Environ 2007; 41: 8140-8149.

54 Korpi A, Järnberg J, Pasanen AL. Microbial volatile organic compounds. Crit Rev Toxicol 2009; 39: 139-193.

55 Moularat S, Robine E, Ramalho O, et al. Detection of fungal development in a closed environment through the identification of specific VOC: demonstration of a specific VOC fingerprint for fungal development. Sci Total Environ 2008; 407: 139-146.

56 Wong J, Magun BE, Wood LJ. Lung inflammation caused by inhaled toxicants: a review. Int J Chron Obstruct Pulmon Dis 2016; 11: 1391-1401.

57 Zock JP, Heinrich J, Jarvis D, et al. Distribution and determinants of house dust mite allergens in Europe: the European Community Respiratory Health Survey II. J Allergy Clin Immunol 2006; 118: 682-690.

58 von Mutius E, Braun-Fahrländer C, Schierl R, et al. Exposure to endotoxin or other bacterial components might protect against the development of atopy. Clin Exp Allergy 2000; 30: 1230-1234.

59 Caillaud D, Evrard B, Laurichesse H, et al. Rôle des endotoxines de l'environnement intérieur dans les symptômes asthmatiques. [Role of indoor endotoxins in asthma symptoms]. Rev Mal Respir 2009; 26: 893-899.

60 Thorne PS, Mendy A, Metwali N, et al. Endotoxin exposure: predictors and prevalence of associated asthma outcomes in the United States. Am J Respir Crit Care Med 2015; 192: 1287-1297.

61 Mustonen K, Karvonen AM, Kirjavainen $\mathrm{P}$, et al. Moisture damage in home associates with systemic inflammation in children. Indoor Air 2016; 26: 439-447.

62 Nevalainen A, Täubel M, Hyvärinen A. Indoor fungi: companions and contaminants. Indoor Air 2015; 25: $125-156$.

63 Mendell MJ, Kumagai K. Observation-based metrics for residential dampness and mold with dose-response relationships to health: a review. Indoor Air 2017; 27: 506-517.

64 Hyvärinen A, Vahteristo M, Meklin $\mathrm{T}$, et al. Temporal and spatial variation of fungal concentrations in indoor air. Aerosol Sci Technnol 2001; 35: 688-695.

65 Frankel M, Timm M, Hansen EW, et al. Comparison of sampling methods for the assessment of indoor microbial exposure. Indoor Air 2012; 22: 405-414.

66 Alanio A, Bretagne S. Difficulties with molecular diagnostic tests for mould and yeast infections: where do we stand? Clin Microbiol Infect 2014; 20: Suppl. 6, 36-41.

67 Vesper S, McKinstry C, Haugland R, et al. Development of an environmental relative moldiness index for US homes. J Occup Environ Med 2007; 49: 829-833.

68 Täubel M, Karvonen AM, Reponen $\mathrm{T}$, et al. Application of the environmental relative moldiness index in Finland. Appl Environ Microbiol 2015; 82: 578-584.

69 Hilton SK, Castro-Nallar E, Pérez-Losada M, et al. Metataxonomic and metagenomic approaches $v s$. culture-based techniques for clinical pathology. Front Microbiol 2016; 7: 484.

70 Karvonen AM, Hyvärinen A, Rintala $\mathrm{H}$, et al. Quantity and diversity of environmental microbial exposure and development of asthma: a birth cohort study. Allergy 2014; 69: 1092-1101.

71 Brooks C, Pearce N, Douwes J. The hygiene hypothesis in allergy and asthma: an update. Curr Opin Allergy Clin Immunol 2013; 13: 70-77.

72 Rook GA. Regulation of the immune system by biodiversity from the natural environment: an ecosystem service essential to health. Proc Natl Acad Sci USA 2013; 110: 18360-18367.

73 Stein MM, Hrusch CL, Gozdz J, et al. Innate immunity and asthma risk in Amish and Hutterite farm children. N Engl J Med 2016; 375: 411-421.

74 Birzele LT, Depner M, Ege MJ, et al. Environmental and mucosal microbiota and their role in childhood asthma. Allergy 2017; 72: 109-119.

75 Shelton BG, Kirkland KH, Flanders WD, et al. Profiles of airborne fungi in buildings and outdoor environments in the United States. Appl Environ Microbiol 2002; 68: 1743-1753.

76 Caillaud DM, Martin S, Ségala C, et al. Airborne pollen levels and drug consumption for seasonal allergic rhinoconjunctivitis: a 10-year study in France. Allergy 2015; 70: 99-106.

77 Madureira J, Paciência I, Cavaleiro-Rufo J, et al. Indoor pollutant exposure among children with and without asthma in Porto, Portugal, during the cold season. Environ Sci Pollut Res Int 2016; 23: 20539-20552.

78 Rocchi S, Reboux G, Frossard V, et al. Microbiological characterization of 3193 French dwellings of Elfe cohort children. Sci Total Environ 2015; 505: 1026-1035.

79 Burr ML, Matthews IP, Arthur RA, et al. Effects on patients with asthma of eradicating visible indoor mould: a randomised controlled trial. Thorax 2007; 62: 767-772.

80 Semple S, Garden C, Coggins M, et al. Contribution of solid fuel, gas combustion, or tobacco smoke to indoor air pollutant concentrations in Irish and Scottish homes. Indoor Air 2012; 22: 212-223.

81 Adams RI, Miletto M, Lindow SE, et al. Airborne bacterial communities in residences: similarities and differences with fungi. PLoS One 2014; 9: e91283. 
Amend AS, Seifert KA, Samson R, et al. Indoor fungal composition is geographically patterned and more diverse in temperate zones than in the tropics. Proc Natl Acad Sci USA 2010; 107: 13748-13753.

83 Sharpe R, Thornton CR, Osborne NJ. Modifiable factors governing indoor fungal diversity and risk of asthma. Clin Exp Allergy 2014; 44: 631-641.

84 Meyers DA, Bleecker ER, Holloway JW, et al. Asthma genetics and personalised medicine. Lancet Respir Med 2014; 2: 405-415.

85 Rava M, Smit LA, Nadif R. Gene-environment interactions in the study of asthma in the postgenomewide association studies era. Curr Opin Allergy Clin Immunol 2015; 15: 70-78.

86 Osborne NJ, Thornton CR, Sharpe RA. Indoor fungal exposure and allergic respiratory disease. Curr Allergy Asthma Rep 2015; 15: 71

87 Bush RK, Portnoy JM, Saxon A, et al. The medical effects of mold exposure. J Allergy Clin Immunol 2006; 117: 326-333.

88 Sharpe RA, Thornton CR, Tyrrell J, et al. Variable risk of atopic disease due to indoor fungal exposure in NHANES 2005-2006. Clin Exp Allergy 2015; 45: 1566-1578.

89 Zhang Z, Reponen T, Hershey GK. Fungal exposure and asthma: IgE and non-IgE-mediated mechanisms. Curr Allergy Asthma Rep 2016; 16: 86.

90 Miller JD, McMullin DR. Fungal secondary metabolites as harmful indoor air contaminants: 10 years on. Appl Microbiol Biotechnol 2014; 98: 9953-9966.

91 Zhang Z, Biagini Myers JM, Brandt EB, et al. $\beta$-Glucan exacerbates allergic asthma independent of fungal sensitization and promotes steroid-resistant TH2/TH17 responses. J Allergy Clin Immunol 2017; 139: 54-65.

92 Crameri R, Garbani M, Rhyner C, et al. Fungi: the neglected allergenic sources. Allergy 2014; 69: 176-185.

93 Twaroch TE, Curin M, Valenta R, et al. Mold allergens in respiratory allergy: from structure to therapy. Allergy Asthma Immunol Res 2015; 7: 205-220.

94 Krieger J, Jacobs DE, Ashley PJ, et al. Housing interventions and control of asthma-related indoor biologic agents: a review of the evidence. J Public Health Manag Pract 2010; 16: S11-S20.

95 Sauni R, Verbeek JH, Uitti J, et al. Remediating buildings damaged by dampness and mould for preventing or reducing respiratory tract symptoms, infections and asthma. Cochrane Database Syst Rev 2015: CD007897.

96 Le Cann P, Paulus H, Glorennec P, et al. Home environmental interventions for the prevention or control of allergic and respiratory diseases: what really works. J Allergy Clin Immunol Pract 2017; 5: 66-79.

97 Lajoie P, Aubin D, Gingras V, et al. The IVAIRE project - a randomized controlled study of the impact of ventilation on indoor air quality and the respiratory symptoms of asthmatic children in single family homes. Indoor Air 2015; 25: 582-597.

98 Pekkanen J, Hyvärinen A, Haverinen-Shaughnessy U, et al. Moisture damage and childhood asthma: a population-based incident case-control study. Eur Respir J 2007; 29: 509-515.

99 Karvonen AM, Hyvärinen A, Roponen M, et al. Confirmed moisture damage at home, respiratory symptoms and atopy in early life: a birth-cohort study. Pediatrics 2009; 124: e329-e338.

100 Schroer KT, Biagini Myers JM, Ryan PH, et al. Associations between multiple environmental exposures and Glutathione S-Transferase P1 on persistent wheezing in a birth cohort. J Pediatr 2009; 154: 401-408.

101 Dales R, Ruest K, Guay M, et al. Residential fungal growth and incidence of acute respiratory illness during the first two years of life. Environ Res 2010; 110: 692-698.

102 Larsson M, Hägerhed-Engman L, Moniruzzaman S, et al. Can we trust cross-sectional studies when studying the risk of moisture-related problems indoor for asthma in children? Int J Environ Health Res 2011; 21: $237-247$.

103 Hwang BF, Liu IP, Huang TP. Molds, parental atopy and pediatric incident asthma. Indoor Air 2011; 21: $472-478$.

104 Hagmolen of Ten Have W, van den Berg NJ, van der Palen J, et al. Residential exposure to mould and dampness is associated with adverse respiratory health. Clin Exp Allergy 2007; 37: 1827-1832.

105 Inal A, Karakoc GB, Altintas DU, et al. Effect of indoor mold concentrations on daily symptom severity of children with asthma and/or rhinitis monosensitized to molds. J Asthma 2007; 44: 543-546.

106 Bundy KW, Gent JF, Beckett W, et al. Household airborne Penicillium associated with peak expiratory flow variability in asthmatic children. Ann Allergy Asthma Immunol 2009; 103: 26-30.

107 Pongracic JA, O’Connor GT, Muilenberg ML, et al. Differential effects of outdoor versus indoor fungal spores on asthma morbidity in inner-city children. J Allergy Clin Immunol 2010; 125: 593-599.

108 Gent JF, Kezik JM, Hill ME, et al. Household mold and dust allergens: exposure, sensitization and childhood asthma morbidity. Environ Res 2012; 118: 86-93.

109 Biagini JM, LeMasters GK, Ryan PH, et al. Environmental risk factors of rhinitis in early infancy. Pediatr Allergy Immunol 2006; 17: 278-284.

110 Osborne M, Reponen T, Adhikari A, et al. Specific fungal exposures, allergic sensitization, and rhinitis in infants. Pediatr Allergy Immunol 2006; 17: 450-457.

111 Jaakkola JJ, Hwang BF, Jaakkola MS. Home dampness and molds as determinants of allergic rhinitis in childhood: a 6-year, population-based cohort study. Am J Epidemiol 2010; 172: 451-459. 